\title{
Etnometodologia: desvelando a alquimia da vivência cotidiana $^{12}$
}

\author{
Ethnomethodology: unveilling the alchemy of everyday life
}

\author{
Samir Adamoglu de Oliveira ${ }^{3}$ \\ Ludmilla Meyer Montenegro ${ }^{4}$
}

\begin{abstract}
Resumo
Este ensaio teórico propõe-se a apresentar uma análise introdutória sobre a etnometodologia, abordagem de pesquisa social empírica surgida a partir dos anos sessenta do século passado que impactou a sociologia desde então ao salientar que os etnometodólogos estudam fenômenos sociais, aqueles que estão disponíveis em atividades humanas incorporadas, sensíveis, de fala e ação. Apresenta-se e discute-se o contexto histórico do seu surgimento, evidenciando suas origens, seus conceitos principais, os elementos filosóficos constitutivos, os métodos e os tipos de pesquisa que essa abordagem comporta e desenvolveu ao longo das últimas décadas; bem como críticas e pontos de convergência com outras abordagens de pesquisa social. Sugere-se a abertura de diálogo entre a etnometodologia e os estudos organizacionais que versam no terreno das práticas sociais, argumentando como, a partir do seu caráter multiparadigmático e multifacetado, a etnometodologia pode ser uma abordagem de pesquisa válida para o estudo qualitativo das organizações. Conclui-se que a etnometodologia parece ser uma possibilidade de aproximação com o fenômeno organizacional que permite compreendê-lo de forma adequada com base na noção de práticas sociais.
\end{abstract}

Palavras-chave: Etnometodologia. Estudos organizacionais. Pesquisa qualitativa. Práticas cotidianas.

\begin{abstract}
This theoretical essay aims to present an introductory analysis of ethnomethodology, an empirical social research approach that arose in the 1960s and has had an impact on sociology ever since, as it underlines that ethnomethodologists study social phenomena, those which are available in the incorporated sensitive human activities of speech and action. For this purpose, some issues are presented and discussed, such as the historical context of its emergence, highlighting its origins, main concepts, constitutive philosophical elements, methods and types of research that this approach encompasses and has developed over the past decades, in addition to criticisms and converging points with other social research approaches. The main intention here is to suggest a dialogue between
\end{abstract}

Artigo submetido em 22 de janeiro de 2011 e aceito para publicação em 20 de julho de 2011.

${ }^{1}$ Os autores gostariam de registrar agradecimento (in memorian) ao Prof. Clóvis L. Machado-da-Silva pela substantiva contribuição que o mesmo prestou às ideias e discussões expostas no corpo deste trabalho, a partir da participação e presença dele na sua versão preliminar, apresentada no VI Encontro de Estudos Organizacionais da ANPAD (EnEO), realizado de 23 a 25 de Maio de 2010, em Florianópolis.

${ }^{2}$ Este trabalho contou com o apoio financeiro da CAPES - Coordenação de Aperfeiçoamento de Pessoal de Nível Superior - para a sua realização.

3

Doutorando em Administração pelo PPGADM/UFPR, Curitiba/PR, Brasil; Mestre em Administração pelo PPGADM/UFPR, Curitiba/PR, Brasil. Endereço: Rua Benjamin Constant, 45, apto 202, Centro, CEP 80060-020 - Curitiba/PR. E-mail: samiroliveira09@hotmail.com; samiroliveira@ufpr.br

4 Doutoranda em Administração pelo PPGADM/UFPR, Curitiba/PR, Brasil; Mestre em Administração pelo PPGADM/UFPR, Curitiba/PR, Brasil. Endereço: Av. Luiz Xavier, 68, apto 2907, Centro, CEP 80020-020, Curitiba/PR. E-mail: ludmilla2907@gmail.com 
ethnomethodology and organizational studies that deal with social practices, discussing how, from its multiparadigmatic and multifaceted nature, ethnomethodology can be a valid research approach for the qualitative study of organizations. In conclusion, ethnomethodology seems to be a possibility for approaching the organizational phenomenon that allows it to be adequately understood based on the notion of social practices.

Keywords: Ethnomethodology. Organizational studies. Qualitative research. Everyday practices.

\section{Introdução}

A etnometodologia, enquanto abordagem teórico-metodológica de pesquisa empírica, surgiu nos anos 1960 nos Estados Unidos, desenvolvendo-se ao longo desta década, mediante uma sistematicidade de pesquisas realizadas, em sua maior parte, por sociólogos descrentes do entendimento de como a ciência da sociologia deveria ser constituída (COULON, 1995; HERITAGE, 1999). Para estes, a preocupação da sociologia deveria ser, em princípio e essência, desvelar a alquimia dos procedimentos cotidianos que formam o tecido social que sustenta as atividades dos indivíduos em caráter contextual - leia-se, situados em um dado tempo e em um dado espaço - (GIDDENS, 2003), seguindo uma orientação hiper-realística de como as atividades comuns e profissionais efetivamente acontecem. Segundo Lynch e Peyrot (1992):

[...] etnometodólogos sustentam que os detalhes imediatos e singulares das ações sociais são ordenados e inteligíveis em sua superfície. Isso não nega a necessidade de competências linguísticas e práticas para produção, reconhecimento e explicação analítica de tais ações; ao contrário, significa insistir que as pessoas que falam e agem em conjunto necessariamente atribuem sentido das ações uns dos outros em "tempo real". [...] Tal "sentido" não é um construto ideal ou intangível, uma vez que ele é incorporado no que as pessoas fazem e dizem de modo patente. Em outras palavras, é tanto reflexivo quanto material. [...] Esse tipo de orientação materialista ou realista difere profundamente do tipo de realismo que trata as "aparências" ordinárias como sendo versões reduzidas do mundo real descrito pela ciência. Ela é mais bem denominada uma orientação "hiper-realística" para os elementos do mundo social que são produzidos, reconhecidos e reproduzidos em atividades tanto de senso comum quanto profissionais. [...] Ao invés de minarem "o que todo mundo sabe", os etnometodólogos tentaram mostrar a extraordinária complexidade e a imersão material dos entendimentos convencionais (LYNCH e PEYROT, 1992, p. 117-118, tradução nossa).

Seguindo essa linha de raciocínio, para se entender o que configura o projeto etnometodológico, percebe-se que este absorve os avanços da filosofia ocidental do início do século XX - em particular, da Fenomenologia alemã, bem como do Empiriocriticismo-Pragmatismo inglês e norte-americano -, contrapondo-os ao padrão Positivista de ciência que vigorava na sociologia da época. Essa junção de elementos aparentemente incongruentes é articulada, em boa parte, a partir de uma preocupação acerca do status ontológico (RAWLS, 2008) que essa ciência deve abarcar, focando no estudo de fenômenos sociais disponíveis em atividades humanas incorporadas, sensíveis, de fala e de ação - sendo este o princípio que une os etnometodólogos (MEHAN e WOOD, 1976). A partir dessa breve exposição dos elementos de partida da etnometodologia, salienta-se a intenção deste ensaio teórico em expor, analítica e introdutoriamente, o quadro teórico de referência que a etnometodologia comporta, evidenciando suas origens, elementos filosóficos constitutivos, tipos de método e de pesquisa, além de críticas reunidas na literatura acerca do tema. Para isso, serão expostos: i) o contexto histórico do seu surgimento; ii) seus conceitos nucleares; iii) os tipos de pesquisa etnometodológica identificados em conjunto com os métodos mais costumeiramente adotados; iv) e, por fim, críticas reunidas da literatura que indicam fraquezas, bem como possibilidades de convergência entre a etnometodologia e abordagens vigentes na pesquisa social. 


\section{Contexto Histórico do Surgimento da Etnometodologia}

Harold Garfinkel inaugura a etnometodologia nos anos 1960, com a publicação da obra Studies in Ethnomethodology (1967), a qual reúne uma série de pesquisas sistemáticas realizadas ao longo dos anos 1950, na Califórnia, em sua maioria coordenadas por ele, após o seu doutoramento em 1952. Nessa época, começaram a ser disseminadas as ideias da abordagem etnometodológica, instigando diversos pesquisadores a empreenderem estudos e a aplicarem métodos específicos de coleta de material empírico para fenômenos sociais de distintas sortes. Dentre esses pesquisadores, muitos vieram a se tornar expoentes respeitados no uso e desenvolvimento de determinadas técnicas, todas aplicadas à luz da intenção etnometodológica de como entender a realidade; - dentre alguns, pode-se citar Aaron V. Cicourel, Harvey Sacks, Don H. Zimmerman, John Heritage, Douglas Maynard, Hugh Mehan, Houston Wood, e J. Maxwell Atkinson.

Acerca da mencionada intenção etnometodológica, já no seu prefácio, e reafirmando isso ao longo da obra, Garfinkel (1967, p. vii-viii, 34, tradução nossa) diz que os estudos de natureza etnometodológica se prestam a analisar as atividades do cotidiano dos indivíduos como sendo "[...] métodos para fazer essas atividades visíveis-racionais-e-reportáveis-para-todos-os-propósitos-práticos, id est., 'relatáveis', como organizações de atividades diárias comuns". Além disso, a reflexividade imanente a tal fenômeno é "um elemento singular das ações práticas, das circunstâncias práticas, do conhecimento de senso comum das estruturas sociais, e do raciocínio sociológico prático". Também é válido frisar que estudos etnometodológicos não visam à prescritividade a partir das análises racionalmente inclinadas dos fenômenos sociais aos quais eles se prestam a fazer, não formulando soluções para ações práticas a partir de julgamentos de valores sobre elas.

Para Garfinkel (1967), a analítica da lógica racional prática para a qual a etnometodologia se volta, é entendida sob a ótica multifacetada dos elementos que uma atividade prática congrega, sendo, sobretudo, uma realização processual contínua e contingente, que delimita espaciotemporalmente o seu acontecimento, envolvendo elementos subjetivos que se cristalizam em propriedades estruturais acessíveis e sustentadas mediante senso comum dos indivíduos que agem nas práticas contextualizadas - sendo, por isso, uma objetividade localizada no tempo e no espaço, direta e indissociavelmente dependente de significados atribuídos, ou seja, uma intersubjetividade (BERGER e LUCKMANN, 2003). Assim, o objeto de estudo da etnometodologia não é algo constante e imutável, mas sim uma realização alcançável mediante um processo socialmente construído (COULON, 1995), tendo por fim não uma mera descrição, mas uma análise interpretativa desse processo e das propriedades pertinentes a este, contudo sem pretender compor prescrições de ação laboral e comunicativa para os fenômenos estudados (MENNELL, 1975).

A partir dessa conceituação, nota-se que diversos elementos teóricos se apresentam articulados na constituição da nova perspectiva de pesquisa que a etnometodologia se propõe a ser, impondo-lhe, por conseguinte, nova postura intelectual. A seguir, serão expostos esses elementos teóricos, suas origens, bem como suas relações com a etnometodologia.

\section{A teoria da ação social de Talcott Parsons}

Tendo sido aluno de Talcott Parsons, a influência do seu pensamento na obra de Garfinkel é perceptível e reconhecida pelo último em sua obra seminal (1967, p. ix), embora de maneira a ser contraposta, e não absorvida. Garfinkel se manifestava contrário ao entendimento que Parsons tinha da dinâmica social, para o qual os modelos normativos da ação humana contemplavam mais uma regulação apriorística das atividades da conduta humana do que uma construção processual como enxergava o precursor da etnometodologia (COULON, 1995). A divergência de Garfinkel residia no entendimento de qual racionalidade Parsons via como imprescindível para a conduta humana. Fortemente influenciado pelo realismo analítico neokantiano, Parsons acreditava em uma conduta de exacerbada racionalidade científica por parte dos indivíduos, nas quais as ações destes definiam normas funcionais para a conduta individual dentro de um sistema social, 
praticamente reduzindo a cognoscitividade dos agentes à mera reprodução dessas funções. $\mathrm{O}$ ponto de divergência principal então residia na racionalidade científica que Parsons acreditava ser, prescritivamente, a ideal para pautar a conduta humana, enquanto Garfinkel acreditava serem a racionalidade prática e o conhecimento de senso comum os elementos cruciais para o entendimento da ação social - elementos construídos e reconstruídos socialmente a partir do processo de interpretação dos indivíduos (HERITAGE, 1999).

A problemática da ação social parsoniana para Garfinkel acabava por constituir indivíduos de juízo dopado, que apenas reproduziam as estruturas sociais normativas numa lógica determinista. $O$ ponto a ser desenvolvido por Garfinkel para superar essa problemática foi encontrado pelo autor a partir da mudança de um paradigma normativo claramente positivista para um paradigma interpretativo da ação humana, articulado mediante as "[...] interpretações do papel da linguagem na ação social, a natureza da intersubjetividade na conduta humana, as bases institucionais da geração e implementação de conhecimento e uma explicação cada vez mais detalhada da natureza da interação social" (HERITAGE, 1999, p. 356-357).

\section{A fenomenologia social de Alfred Schutz}

Alfred Schutz inaugurou durante a primeira metade do século XX uma fenomenologia de natureza social, desenvolvendo os pressupostos da fenomenologia husserliana sob uma ótica do conhecimento do senso comum largamente social em sua constituição, cujo processo mediador crucial era a interpretação (PSATHAS, 2004). Segundo a concepção desse fenomenólogo, a interpretação do mundo se dá mediante categorias e construtos do senso comum que são largamente sociais em sua origem, e que representam recursos com os quais os agentes interpretam suas situações vividas de ação e interação no plano social. Para Schutz, os objetos para os quais os agentes se orientam são ativamente constituídos no fluxo das experiências por intermédio de uma série de operações subjetivas, tendo o conceito de construção (ou constituição) particular significação nesse contexto. Tanto para os objetos naturais, quanto para os sociais, a construção/constituição é necessária e continuamente atualizada por meio de sínteses de identificação interminavelmente renovadas. É somente dessa maneira que os objetos (físicos e sociais) são estabilizados como objetos auto-mesmos, apesar das mudanças nas perspectivas físicas a partir das quais eles são vistos e, no caso dos objetos animados, a despeito de suas formas mutáveis e de suas variadas manifestações comportamentais.

Diante da recorrência desse processo, os objetos do mundo social são constituídos no interior de uma estrutura de familiaridade e pré-convivência fornecida por um estoque de conhecimentos à mão que é essencialmente social em sua origem. Esse estoque de construtos sociais é mantido numa forma tipificada, constituindo, com isso, um conhecimento tipificado à luz do qual os agentes analisam o mundo social de maneira aproximada e revisável, servindo como recursos paradigmáticos para a organização da ação. Uma vez que esse processo ativo nunca se dá isoladamente, mas sempre no plano social, Schutz propôs que a compreensão intersubjetiva dos atores se realize por meio de um processo ativo no qual os participantes admitem a tese geral da reciprocidade das perspectivas, a qual significa dizer que apesar das diferentes perspectivas, biografias e motivações que levam os agentes a terem experiências do mundo não idênticas, eles podem, ainda assim, tratar as suas experiências como idênticas para todos os fins práticos (HERITAGE, 1999). A partir da concepção fenomenológica de uma realidade intersubjetivamente sustentada, Garfinkel assumiu, em contraposição à lógica da Teoria da Ação parsoniana, que os indivíduos sabem, de certa maneira e em algum grau, o que estão fazendo em circunstâncias de interação social com outros indivíduos. Assim, a preocupação garfinkeliana com a questão da ação humana começa a tomar um contorno diferente daquele presumido por Parsons, à medida que aquele desloca a sociologia para o terreno do raciocínio prático do senso comum diante das situações mundanas enfrentadas pelos indivíduos (COULON, 1995; GIDDENS, 2003; HERITAGE, 1999). 
Porém, é crucial destacar que, ao contrário do que uma leitura superficial pode supor, a etnometodologia não constitui uma derivação da Fenomenologia Social de Alfred Schutz, muito menos parte de onde esta parou para desenvolver um novo campo fronteiriço entre Filosofia e Sociologia. O que a etnometodologia, enquanto abordagem de pesquisa empírica faz, é apropriar-se de argumentos, pressupostos, e variações de procedimentos dessa Fenomenologia em específico, para desenvolver elementos teóricos robustos o suficiente que possam ancorar a sua concepção de como entender a realidade a partir das questões de raciocínio prático cotidiano optando, com isso, pela via da intersubjetividade para superação do problema da primazia da ideia ou da matéria (PSATHAS, 2004). Ao optar por essa via, que pressupõe um processo contínuo e sempre decorrente da intencionalidade dos agentes que se voltam para a interação social, a etnometodologia aceita a ideia fenomenológica da realidade enquanto devir, sedimentando parcialmente ou seja, cristalizando - as propriedades estruturais das ações dos indivíduos, tornando-as sempre passíveis de (re)criação. Assim, os elementos fenomenológicos que se encontram na etnometodologia são: i) as pressuposições de se pôr entre parênteses os fenômenos e as teorias sobre o mundo social, mantendo com isso uma atitude de indiferença etnometodológica para com elas; ii) a requisição de uma fidelidade para com o fenômeno em estudo; iii) a aceitação das qualidades humanas de pensamento, razão, emoções e agregados sensíveis, planejamento, julgamentos, e conhecimentos presentes nas ações humanas; iv) rejeições a prescritividades e pré-formulações de métodos e estratégias de análise metodológicas, diante da singularidade de cada fenômeno social abordado; v) cuidado na manutenção dos aspectos fidedignos das descrições dos métodos práticos dos membros nos seus atos de falar e de agir no mundo cotidiano; e vi) abandono de monismos causais nas explanações analíticas a que se prestam seus estudos (PSATHAS, 2004).

Esses elementos fenomenológicos presentes na etnometodologia compartilham ainda a ideia de que a colocação entre parênteses (a suspensão e não a negação) das teorias sobre o mundo social possibilita ao observador-pesquisador aproximar-se daquilo que os próprios membros da vida cotidiana produzem interpretativamente e reconhecem como realidade, retomando a ideia fenomenológica de reposição das essências na existência, pois "o mundo é não aquilo que eu penso, mas aquilo que eu vivo; eu estou aberto ao mundo, comunico-me indubitavelmente com ele, mas não o possuo, ele é inesgotável" (MERLEAUPONTY, 1999, p. 14). A intersubjetividade, esse caráter compartilhado da interação cotidiana, é uma realização ininterrupta, um conjunto de entendimentos sustentados momento a momento pelos participantes em interação (HOLSTEIN e GUBRIUM, 1994). Assim, para aproximar-se da realidade (considerada como uma construção social), tanto fenomenólogos, quanto etnometodólogos concordam que a pesquisa em ciências sociais deve atentar para o conhecimento do senso comum e para as razões práticas dos sujeitos no mundo social.

Essas concepções, apreendidas e adaptadas ao corpo da proposta etnometodológica, visam reforçar a mutualidade constitutiva entre os planos objetivo e subjetivo que as interações espaciotemporalmente localizadas entre os indivíduos abarcam. Diante disso, a realidade é percebida como socialmente construída por meio das interações sociais dos sujeitos que subjetivamente percebem essa realidade como dotada de uma realidade objetiva e intersubjetivamente a legitimam, dotando-a de uma quase materialidade que possibilita o convívio humano em uma rede de significados comuns, pautados nos estoques de conhecimento do sujeito e nas tipificações que permeiam o mundo social e possibilitam a interação intersubjetiva entre os sujeitos.

\section{O interacionismo simbólico da escola de Chicago}

Também ancorado na lógica de que há uma mutualidade constitutiva entre os planos objetivo e subjetivo, a corrente do Interacionismo Simbólico advoga em favor de um entendimento dos indivíduos mais como atores na criação do mundo vivido. Para eles, há sempre um papel criativo na construção social da vida cotidiana, focando mais fortemente na questão dos simbolismos e dos significados que os objetos sociais recebem no decorrer das interações entre os atores. Dessa forma, não se trata de fatos sociais - nos termos 
durkheimianos, nos quais teríamos novamente uma lógica positivista operante, estabelecendo o plano social e os fenômenos pertinentes a este como algo dado -, mas de objetos sociais sempre passíveis de interminável (re)construção dada a fragilidade, a temporalidade e a breve durabilidade com as quais os processos interativos são encarados, segundo essa corrente de pensamento (JOAS, 1999).

A influência dessa escola de pensamento - cuja obra de George Herbert Mead constitui um dos seus principais pilares - para a etnometodologia reside na atribuição de significado (em termos específicos, rótulos) às ações e às falas dos indivíduos em circunstâncias de interação, as quais, mesmo à luz de normas socialmente estabelecidas, nunca são definidas unilateralmente, muito menos reificadas objetivamente, mas sempre são sustentadas comportamentalmente em processos de negociação de significados (COULON, 1995).

\section{A pragmática da linguagem de Ludwig Wittgenstein}

Diante do pervasivo entendimento de que a realidade socialmente construída é algo processual, sempre passível de reconstrução devido a novas possibilidades interpretativas que surgem no decorrer das ações práticas, nas quais está compreendida, evidentemente, a fala, alcança-se a última - mas não menos importante - corrente de pensamento à qual recorre a etnometodologia, ao menos em alguns segmentos específicos que privilegiam mais a ação conversacional (MENNELL, 1975; MAYNARD e CLAYMAN, 1991). Trata-se da filosofia da linguagem, também denominada pragmática da linguagem, cujo principal representante, indubitavelmente, é o filósofo austríaco Ludwig Wittgenstein. Segundo este, a realidade para um indivíduo, enquanto um mundo compartilhado, só pode fazer sentido mediante a inserção deste numa determinada linguagem, na medida em que as palavras e expressões vão adquirindo seus significados de acordo com os contextos práticos (ou formas de vida) nos quais vão sendo utilizadas. Em outros termos: a compreensão, interpretação e inserção do indivíduo numa realidade só são possibilitadas pelas propriedades da linguagem humana e pela flexibilidade de usos e significados que as expressões gramaticais vão adquirindo no seu contexto prático, mediante o que se conceitua como jogos de linguagem, entendidos como "a totalidade formada pela linguagem e pelas atividades com as quais ela vem entrelaçada" (WITTGENSTEIN, 2009, p. 19).

Segundo essa concepção filosófica, a linguagem não representa fielmente o mundo, pois esta possui sua própria lógica, e as expressões gramaticais vão ganhando novos significados de acordo com os contextos práticos em que vão sendo lidas e ditas, de maneira que, se uma palavra tem um sentido/significado atribuído a ela, esse é um processo que só ocorre no uso dessa palavra na linguagem. Com efeito, a etnometodologia recorre a esse pressuposto pelo fato de negar quaisquer apriorismos, inclusive no que concerne à fala e à linguagem (ZIMMERMAN, 1978). Assim, uma vez que os sistemas que o conjunto de práticas cotidianas que os indivíduos constituem é levado adiante, enquanto processo interativo, mediante o uso da linguagem, faz-se crucial o entendimento desse elemento para todo o processo de construção social da realidade (BERGER e LUCKMANN, 2003).

\section{Conceitos-Chave da Etnometodologia}

De acordo com as perspectivas citadas, que explicam, em termos de proveniência, o surgimento da concepção etnometodológica, pode-se afirmar que a etnometodologia não trata de um método, mas de uma abordagem teórico-metodológica de pesquisa, a qual situa, no cerne da sua proposta, o estudo dos métodos que os membros da sociedade empregam, de maneira conjunta, para organizar as definições das atividades práticas diárias (MEHAN e WOOD, 1976; ZIMMERMAN, 1976). A etnometodologia é assim compreendida, porque ela pretende investigar os métodos; logo, não faz sentido entendê-la como um 
método em si, isolado (SHARROCK, 2003). Ao situar ontologicamente o processo de interação dos indivíduos na dinâmica das práticas cotidianas, duas questões são imediatamente postas ao programa etnometodológico: a distinção entre o conteúdo e forma da interação social. No que concerne ao conteúdo, este diz respeito a o que é feito na interação social, segundo o entendimento dos indivíduos que participam da interação, ou mesmo aos olhos do sociólogo observador - ou seja, aos olhos dos praticantes leigos, ou aos olhos dos profissionais científicos (GARFINKEL, 1967). No que concerne à forma, esta diz respeito ao como as atividades em questão são realizadas, e esta (a forma) só é acessível ao etnometodólogo a partir do instante em que este suspende - pondo entre parênteses, fenomenologicamente falando - a preocupação com o que é feito para apreender a maneira como as atividades práticas em si são feitas, mediante diferentes técnicas de codificação para, a partir desta sistematização de material empírico, poder interpretar os significados relacionados e sustentados nos contextos das ações dos indivíduos (MEHAN e WOOD, 1976; ZIMMERMAN, 1976). É somente ao ser colocada tal distinção que a palavra etnometodologia consegue obter sentido, em termos etimológicos:

A abordagem etnometodológica estuda os métodos que efetivamente são praticados (usados) pelos membros da sociedade a fim de alcançar (fazer) o que quer que seja que eles estão fazendo (incluindo as formas de falar a respeito do que quer que seja que eles estão fazendo). Um estudo sério e cuidadoso dos métodos usados pelos membros para alcançar ações práticas no mundo da vida cotidiana resulta em descrições e análises da metodologia de todo dia ou da etno (membro de um grupo ou do próprio grupo em si) metodologia, ou dos métodos dos membros. A parte referente à metodologia do termo etnometodologia deve ser entendida como se referindo ao "como" as efetivas práticas situadas, os métodos pelos quais as atividades de todo dia são alcançadas (PSATHAS, 2004, p. 32, grifo do autor, tradução nossa).

Diante desse empreendimento de pesquisa, pode-se vislumbrar com mais acurácia quais são os conceitos nucleares da etnometodologia, ao mesmo tempo em que se poderá notar que eles são interdependentes.

\section{Práticas e realizações}

Segundo Garfinkel (1967, p. 1, tradução nossa), práticas são entendidas, no contexto da abordagem etnometodológica, como consistindo em "[...] realizações contingentes, contínuas e infinitas" que são conduzidas com o suporte de organizações ou de indivíduos - com conhecimentos internalizados, reconhecimento de conduta reflexiva e senso comum - em específico e que acontecem como eventos na mesma disposição ordinária que elas organizam. Essas atividades práticas revelam as regras e o modus operandi dos indivíduos envolvidos nas interações sociais contextualizadas, levando, dessa forma, a uma lógica circular para o entendimento da relação entre essas práticas e as propriedades estruturais que estas congregam (COULON, 1995; GIDDENS, 2003).

\section{A indicialidade (indexicality)}

Define Coulon (1995, p. 33) que a indicialidade é um termo adaptado da linguística que corresponde a “[...] todas as determinações que se ligam a uma palavra, a uma situação". A indicialidade de uma palavra ou de uma atividade ratifica o caráter situacional de uso de um termo ou de um procedimento laboral, já que estes possuem significados transituacionais, tendo um sentido distinto em toda situação particular em que é usada, urgindo, por conseguinte, que esta seja indexada a uma situação de intercâmbio linguístico. Esse conceito da etnometodologia recorre aos pressupostos explicitados pela pragmática da linguagem wittgensteiniana, à 
atribuição contextual de significados do interacionismo simbólico, e à questão do uso atrelado à existência que a fenomenologia social defende, a partir da objetividade situada no tempo e no espaço que a intersubjetividade representa. Em resumo, as propriedades indicativas decorrem, em última análise, de seu caráter como ações, uma vez que as explicações estão inextricavelmente ligadas às ocasiões de seu uso (HERITAGE, 1999; WITTGENSTEIN, 2009).

\section{A reflexividade}

A reflexividade compreende as propriedades racionais reconhecíveis por parte dos indivíduos a partir do senso comum que estes têm das coisas que dizem ou fazem nos seus contextos de interação (GARFINKEL, 1967). A reflexividade é um elemento tanto de partida quanto de chegada para a cognoscitividade dos indivíduos no que tange à habilidade de estes descreverem e/ou produzirem uma ação em circunstâncias de interação. Como afirma Garfinkel (1967, p. 8, tradução nossa), "membros sabem, requerem, contam com, e fazem uso desta reflexividade para produzir, realizar, reconhecer, ou demonstrar adequabilidade-racionalpara-fins-práticos dos seus procedimentos ou achados". Essa reflexividade propicia uma segurança ontológica para a ação dos indivíduos (GIDDENS, 2003), por gerar a chamada "cláusula de et cetera" (GARFINKEL, 1967, p. 74, tradução nossa), mediante a qual os indivíduos são providos de uma (mínima) certeza de que, mesmo diante de condições desconhecidas, há (ou pressupõe-se que haja) um conhecimento do senso comum de como agir e falar frente a tais circunstâncias, dando-lhes condições de previsibilidade para como reagir de acordo com as ações que irão suceder na interação. Resumindo, reflexividade para Garfinkel "significa que a próxima coisa a ser dita, feita ou vista reflete retrospectivamente na última coisa e tem o potencial de mostrá-la sob uma nova luz" (RAWLS, 2008, p. 713, tradução nossa).

\section{A relatabilidade (accountability)}

Este conceito é diretamente relacionado ao conceito de reflexividade, por apoiar-se na lógica de que, se há uma reflexividade consciente, esta pode ser minimamente descrita mediante a linguagem, tornando-a, portanto, inteligível e descritível - ou seja, relatável (COULON, 1995). Dessa forma, retornamos novamente à questão da pragmática da linguagem wittgensteiniana criando mundos e realidades a partir da linguagem em uso, indicando-nos que essa relatabilidade, muito mais do que meras descrições, são contínuas demonstrações de que o mundo é um processo incessante de constituição por meio do uso da linguagem, do senso comum, das realizações práticas, das atividades procedurais mais elementares que acabam constituindo os tecidos sociais em interações contextualizadas.

\section{A noção de membro}

Congregando esses conceitos, temos a noção de membro, que corresponde à inserção de um indivíduo num específico contexto de grupo (uma instituição social, por exemplo), mediante o acesso a uma (ou a um conjunto de) prática(s), a partir do domínio de uso da linguagem natural (COULON, 1995). Independentemente de serem indivíduos leigos ou profissionais, a noção de membro não é associada a coletivos organizados, mas sim a coletividades, nas quais a questão da intersubjetividade formulada e sustentada a partir do senso comum, da reflexividade pressuposta nas ações e falas das interações, e da relatabilidade que estas interações podem disparar enquanto metaconversações (ROBICHAUD, GIROUX e TAYLOR, 2004), são administradas puramente de acordo com a capacidade que os indivíduos têm de dominar naturalmente um "[...] conjunto de modos de agir, de métodos, de atividades", de uso da linguagem, para dar sentido ao mundo que as cercam (COULON, 1995, p. 48). 


\section{A noção de grupo}

Garfinkel enfatiza que agentes situados, engajados na construção de uma ordem sequencial de significado, constituem um grupo somente quando o caráter sequencial de a interação na qual eles estão engajados requerer deles, coletivamente, um comprometimento mútuo para as propriedades constitutivas da situação. $\mathrm{O}$ grupo, enquanto uma reunião de procedimentos interpretativos, perpetua-se à medida que seus membros interagem. Convém salientar o caráter contínuo do grupo, uma vez que agentes podem ir e vir, porém, enquanto houver interação, ele não deixa de existir (RAWLS, 2008).

\section{A Questão do Método na Etnometodologia}

O termo etnometodologia não é facilmente compreendido. Em parte, porque alguns estudiosos o entendem como uma nova metodologia da etnologia. Diante disso, convém resgatar que, na sua origem, a palavra foi cunhada por Garfinkel como a ciência (logos) dos etnométodos, ou seja, dos procedimentos que constituem o que autor denomina de raciocínio sociológico prático (COULON, 1995).

Garfinkel tece críticas sobre a sociologia tradicional ao mencionar que nesta o homem observado pelo sociólogo é fictício, é uma construção cuja racionalidade não tem outro objetivo senão verificar a pertinência do modelo. É um homem que não tem biografia, não tem história, não tem paixões (GARFINKEL, 1967).

É importante destacar que a pesquisa sociológica repousa sobre uma visão tácita do mundo, de senso comum. Tanto que, ao falar em estatísticas, os etnometodólogos posicionam-se muito fortemente, pois, para eles, as estatísticas que muitas vezes são consideradas e utilizadas como limites confiáveis, indicadores seguros, são tratadas da seguinte forma: elas passam pelas capacidades de julgamento dos agentes que coletam e verificam os dados, ou seja, não há como não interpretar os números de uma análise estatística. Os etnometodólogos acreditam que a sociologia praticamente não ultrapassou ainda a fase da atitude natural da fenomenologia. Assim, convém destacar que o trabalho da etnometodologia não consiste em modificar, contribuir, detalhar, dividir, explicar, fundamentar a relação ao raciocínio sociológico profissional. A preocupação da etnometodologia é com o raciocínio sociológico prático (COULON, 1995).

Com relação à provocação experimental, Garfinkel relata, em sua obra Studies in Ethnomethodology, muitas observações, experiências e até mesmo experimentos em que se empreende uma desarrumação (breaching) das rotinas. Segundo Parsons, as rotinas se fundamentam em uma ordem moral que é necessária para a realização de nossas ações. Na etnometodologia de Garfinkel, é importante ressaltar que a necessidade de uma ordem moral como garantia para o bom êxito das interações se transpõe para a questão da confiança (COULON, 1995). Nas concepções desse autor, confiança não é uma atitude e só pode ser perdida (não se pode ganhar confiança, uma vez que ela é requerida desde o começo - a confiança é tácita). Assim, a questão principal, para a etnometodologia, diz respeito à relação de confiança que está por trás das regras do jogo. $\mathrm{O}$ fato de romper a regra do jogo não é o mais importante. Para Garfinkel, "[...] a confiança deve ser pressuposta, primeiramente, por todos os membros de uma prática, e então confirmada constantemente por meio de várias formas de atenção e competência" (RAWLS, 2008, p. 712, tradução nossa). É importante elucidar que essa definição de confiança é bem diferente da comumente utilizada nos estudos organizacionais e sociais.

Outro aspecto da etnometodologia que merece destaque é que os procedimentos utilizados pelos etnometodólogos não são próprios, não são novos. As técnicas aplicadas tanto por Garfinkel, quanto por seus seguidores fazem parte do patrimônio da sociologia qualitativa moderna. Garfinkel enfatiza que não se trata de apontar o que está errado na sociologia padrão e dizer quais os métodos corretos que devem ser utilizados nas pesquisas, nem escrever um novo capítulo de metodologia para os manuais de sociologia, mas criticar esses métodos que se configuram como o padrão (principalmente os quantitativos). De acordo com Cicourel, 
os sociólogos não atribuem suficiente importância ao estudo das variáveis subjetivas, em particular as que contribuem para o caráter contingente da vida cotidiana (COULON, 1995).

Ao mencionar que os procedimentos utilizados pelos etnometodólogos não são novos, faz-se necessário exemplificá-los. Muitos dos instrumentos de pesquisa utilizados em um estudo etnometodológico são emprestados da etnografia. Um enfoque interessante, inspirado na etnometodologia e proposto por Hugh Mehan, é o da etnografia constitutiva: "os estudos da etnografia constitutiva funcionam a partir da hipótese interacionista segundo a qual as estruturas sociais são construções sociais" (COULON, 1995, p. 86). Essa orientação teórica está pautada em quatro grandes princípios: (1) a disponibilidade dos dados consultáveis (documentos em áudio e vídeo, etc.); (2) a exaustividade do tratamento dos dados; (3) a convergência entre os pesquisadores e os participantes sobre a visão dos acontecimentos (utilizando técnicas como a entrevista recorrente, por exemplo); (4) a análise interacional, que evita ao mesmo tempo redução psicológica e a reificação sociológica. Nessa concepção, é possível reconhecer um dos princípios fundamentais da etnometodologia: os fatos sociais são construções práticas. Também convém ressaltar que, como a organização dos acontecimentos é socialmente construída, há de se procurar essa estruturação nas expressões e nos gestos dos participantes. Os etnometodólogos também fazem uso de métodos empregados por outras sociologias qualitativas, em que os instrumentos para coleta de material empírico são: observação direta, observação participante, diálogos, gravações em vídeo, projeção do material gravado para os próprios autores, gravações dos comentários feitos no decorrer dessas projeções, entre outros (COULON, 1995). Observa-se, nos estudos etnometodológicos, um foco na descrição, uma vez que "como a etnometodologia fixa para si o objetivo de mostrar os meios utilizados pelos membros para organizar a sua vida social comum, a primeira tarefa de uma estratégia de pesquisa etnometodológica é descrever o que os membros fazem" (COULON, 1995, p. 89). Zimmerman (1978) enfatiza que "o etnógrafo deve encontrar os meios para estar onde tem que estar, ver e ouvir o que pode, desenvolver a confiança entre ele e os sujeitos a estudar, e fazer muitas perguntas" (COULON, 1995, p. 90); por isso esse autor faz uso do tracking, que significa, nos estudos etnometodológicos, seguir a pista de alguém, ficar na espreita.

Diante disso, convém frisar que a construção do mundo social pelos membros é metódica. Apoia-se nos recursos culturais comuns que permitem não somente construí-los, mas reconhecê-lo, pois só quando se sabe como os membros constroem as suas atividades é que se pode ter razoável certeza do que são realmente essas atividades (COULON, 1995). É possível perceber que a concepção etnometodológica é fundamentalmente construtivista, e sendo construtivista, a etnometodologia oferece outro caminho para o problema da objetividade dos problemas da realidade prática, já que segundo seu alinhamento ontológicoepistemológico, metodologias e métodos desempenham um papel constitutivo na produção de todo e qualquer fenômeno social a ser analisado, sugerindo com isso, não uma descrença na metodologia e no método, mas sim uma descrença na lógica de tábula rasa e de pureza analítica que algumas metodologias e métodos na pesquisa social pressupõem ter, segundo as quais um efetivo e completo distanciamento dos elementos subjetivos dos pesquisadores seria possível (LYNCH, 2001; SHARROCK, 2003).

É importante elucidar que os etnometodólogos desenvolveram, desde o início do movimento, a maioria de seus estudos com relação a problemas de sociedade. Os estudos de Garfinkel, por exemplo, são sobre tribunais, decisões tomadas pelos jurados, criminologia, pesquisas sobre o suicídio, entre outros. Convém ressaltar ainda que a posição de Garfinkel não é antropológica, com exceção da característica altamente etnográfica de pesquisa (RAWLS, 2008). Nos estudos organizacionais, também existem estudos etnometodológicos clássicos, como o de Bitter (uma análise crítica do conceito de organização e do tipo ideal weberiano) e o estudo de Zimmerman (1978) (estudo sobre as interações no interior do sistema organizacional). Porém outros estudos etnometodológicos também foram/são empreendidos na área dos estudos organizacionais, contudo mais presentes fora do cenário brasileiro. 


\section{A Etnometodologia nos Estudos Organizacionais}

As noções de Garfinkel sobre questões tidas como dadas (taken for granted issues) e a importância geral de detalhes sobre ordem, explicações e focos de atenção vêm desde a década de sessenta influenciando os trabalhos de autores renomados na área de estudos organizacionais, tais como: Egon Bitter, Karl Weick, John Van Maanen, Steve Barley, e Peter K. Manning (RAWLS, 2008).

Convém salientar que, apesar do impacto de Garfinkel nos estudos sobre o trabalho, sua contribuição teórica permanece obscura, o que gera algumas discussões, tais como: os estudos etnometodológicos são desprovidos de uma orientação teórica adequada? Sabe-se que os estudos etnometodológicos são sim, baseados em premissas teóricas, elaboradas por Garfinkel principalmente em publicações e manuscritos escritos entre 1940 e 1967, que desafiam teorias e pesquisas convencionais de forma significativa. Garfinkel insiste que a inteligibilidade mútua (ou sensemaking) em todas as situações, desde conversações comuns no trabalho nas mais altamente estruturadas organizações, requer atenção constante e uso competente de métodos compartilhados de ação organizada para que ela possa acontecer. Mais especificamente, Garfinkel enfatiza que os métodos essenciais para o trabalho serão encontrados em detalhes de atenção, em métodos de trabalho orientados, e em propriedades ordenadas de ação mútua, e não em formulações abstratas. As contribuições mais originais de Garfinkel para a teoria social referem-se à compreensão de que o significado requer ordem e à elaboração empírica de como isso acontece por meio de instrumentos sequenciais e da atenção reflexiva. Para esse autor, "ordem = significado" (RAWLS, 2008, p. 709, tradução nossa). Todavia é importante frisar que, para esse autor, as contingências das ordens locais são muito complexas e mutáveis para serem compostas por uma unidade padrão - hábitos, rotinas, regras, definições, símbolos, etc. Por isso, ele enfatiza que essas unidades só possuem um significado compartilhado e reconhecido para um grupo de trabalho quando elas são construídas por meio de métodos compartilhados para criar uma ordem situada. Não são as unidades que geram uma constante, e sim as propriedades de ordem agindo constantemente (com base na lógica de um caleidoscópio) em que objetos mutuamente inteligíveis geram uma constante. Assim, percebe-se que há uma preocupação epistemológica - de como se acessa a realidade - e não ontológica - de como simplesmente a realidade é, lembrando que "epistemologia tem a ver com a forma pela qual nós entendemos e descrevemos o mundo, e ontologia tem a ver com a forma como o mundo é" (CILLERS, 2002, p. 78, tradução nossa).

Também é importante ressaltar, com o intuito de justificar que a etnometodologia de Garfinkel não tem o foco em questões individuais, que a preocupação desse autor é com as maneiras padronizadas nas quais as propriedades de ordem da ação situada tornam-se públicas. Para Garfinkel, interesses e atitudes individuais são irrelevantes para ordens situadas porque cada ação, para ser significativa, deve exibir ordem independentemente de motivações individuais particulares (RAWLS, 2008). É justamente a partir desse ponto que se vislumbra, aqui, uma ampliação de níveis de análise, passando-se de um plano estritamente individual a um plano de grupo em contexto organizado (para fins de construção de significados atrelados a ordens e padrões de conduta, conforme antes mencionados), o qual sugere-se ser uma possibilidade de diálogo entre a etnometodologia e os estudos organizacionais.

\section{Etnometodologia x sensemaking}

Embora haja uma similaridade entre as concepções teóricas do sensemaking de Weick (1995) e os pressupostos da etnometodologia, bem como foi referenciado no primeiro parágrafo desta seção, convém ressaltar que na etnometodologia parece haver uma preocupação maior com a sequência, com a ordem dos fatos, bem como com a maneira pela qual os fatos sociais são construídos, por mais que se saiba que a máxima do sensemaking seja tentar tornar o abstrato tangível (WEICK, 1995) e que, em ambas as concepções, há uma ênfase na intersubjetividade dos sujeitos a partir de uma base comum, que é a Fenomenologia. 
Aparentemente, a etnometodologia se propõe a estudar mais a fundo os métodos compartilhados - por meio de observações, transcrições, entrevistas recorrentes - enquanto o sensemaking parece concentrar-se nas percepções e interpretações e na construção de narrativas, mesmo que haja uma forma de sistematização das informações - como ocorre no modelo de organizing de Weick, em que as informações são processadas à medida que passam pelas fases de criação, seleção e retenção, em que, ao final, as informações retidas são menos ambíguas do que no início do processo, visto que regras e ciclos de comportamento foram "rodados" em cada fase com o intuito de reduzir a ambiguidade inicial.

Neste ponto, convém resgatar as sete propriedades do sensemaking: (1) baseado na construção da identidade - um sensemaker nunca age sozinho porque sua identidade é construída a partir da interação com os outros, o que caracteriza um tipo de identidade coletiva; (2) caráter retrospectivo - a criação de significado é tida como um processo de atenção àquilo que já ocorreu, então a atenção é direcionada "para trás" a partir de um ponto específico no tempo e, como o texto para ser interpretado já ocorreu, e é só uma memória, qualquer coisa que afetar o processo de lembrar irá afetar o sentido que é dado a essas memórias; (3) criado em ambientes sensatos - para Weick, não há um ambiente monolítico e fixo que existe separadamente das pessoas; estas fazem parte de seus próprios ambientes criados; (4) social - o sensemaking nunca é solitário porque o que uma pessoa faz internamente é contingente aos outros; mesmo a inação é contingente aos outros; (5) dinâmico - o sensemaking não tem um ponto de início; isso se dá porque as pessoas estão sempre no meio de coisas, de fluxos contínuos; (6) focado em e por dicas extraídas - dicas extraídas são estruturas familiares e simples, consideradas como sementes a partir das quais as pessoas desenvolvem um sentido mais amplo sobre o que pode estar ocorrendo; e (7) guiado pela plausibilidade em vez de pela precisão - o sensemaking não é sobre verdade nem certeza, mas sobre a reformulação contínua de uma estória emergente para que ela se torne mais compreensiva (MONTENEGRO, 2009).

Um ponto em que as concepções do sensemaking e a etnometodologia parecem dialogar é na questão da identidade. Uma vez que, para Garfinkel, identidades individuais só existem (e só podem ser vistas, reconhecidas e entendidas) dentro de situações sociais, ou grupos, definidos por maneiras compartilhadas de produzir ordem em detalhes (RAWLS, 2008), percebe-se que esse pressuposto corrobora a primeira propriedade do sensemaking, visto que neste o foco também é na interação e na identidade coletiva - vide a noção de membro na etnometodologia. Percebe-se que também há uma coerência do caráter retrospectivo do sensemaking com algumas considerações da etnometodologia de Garfinkel (retomando o caráter de reflexividade), quando esse autor menciona que métodos (ou práticas) para produzirem objetos e ações mutuamente inteligíveis requerem uma orientação mútua constante e uma sustentação na confiança, levando em conta que cada coisa feita ou dita na sequência refere-se à última (reflete na última - caráter retrospectivo) e essa corrente sequencial reflexiva constitui a ordem básica para o sensemaking (RAWLS, 2008). Outro ponto em que se verifica a coerência das duas abordagens é com relação ao sensemaking ser dinâmico. Garfinkel menciona que o sensemaking colaborativo não é simplesmente algo que acontece quando as coisas são interrompidas; ele está acontecendo em todo momento significativo (RAWLS, 2008).

Já um ponto divergente diz respeito à noção de grupo que cada um dos autores desenvolve (para a definição de grupo de Garfinkel, ver seção 3.6). Weick, ao tratar de grupo, refere-se à mente grupal (group mind) e essa ideia de mente grupal sugere que o caráter mútuo das relações consiste em uniões misteriosas de mentes. Para Garfinkel, não há mistério: existem práticas de atenção e sensemaking muito específicas e empiricamente observáveis que constituem a coerência de um grupo de trabalho (RAWLS, 2008). Essas definições parecem ser influenciadas pelos pressupostos de cada autor, lembrando que Weick se baseia na Psicologia Social - foco no aspecto cognitivo, enquanto Garfinkel se baseia numa Sociologia com foco na prática. Finalmente, é possível observar no excerto abaixo como a etnometodologia delineia seus alinhavos, evidenciando os métodos (ou práticas) como essenciais para o fenômeno do sensemaking. É somente ao se tratarem "objetos, identidades, e ordens como coisas sociais realizadas situadamente, por pessoas, utilizando métodos ou práticas compartilhados para tal, que se é possível falar na realização do fenômeno social (e essencial) do sensemaking", (RAWLS, 2008, p. 723, tradução nossa), pois é a partir disso que as configurações de natureza complexa envolvendo contingência e incerteza que permeiam o cotidiano das organizações sociais podem ser entendidas. Assim, pode-se observar que, para que sejam empreendidos os 
mecanismos de sensemaking, relacionados à percepção e à interpretação, é preciso que se entenda a prática situada dos agentes no dia a dia, papel a que se propõe a etnometodologia, pois, desta forma, a imersão nas atividades cotidianas e a consequente construção de narrativas irão auxiliar o processo de redução de incertezas e ambiguidades, as quais são enfrentadas pelos agentes nas organizações - indicando, com isso, uma forte relação de complementaridade entre a concepção etnometodológica de pesquisa social, e o sensemaking weickiano.

\section{Debatendo a Etnometodologia: Críticas, Respostas e Caminhos}

Até o surgimento da obra de Garfinkel, Studies in Ethnomethodology, não havia acontecido um questionamento tão radical da Sociologia. O principal ataque à ideia etnometodológica aconteceu em agosto de 1975. Lewis Coser, então presidente da Associação Americana de Sociologia, que contava na época com oito mil membros, fez um discurso hostil na abertura do Congresso Anual da Associação. O foco do seu pronunciamento eram duas questões referentes à Sociologia americana: a análise quantitativa e a etnometodologia. Com relação à etnometodologia, Coser (1975) mencionou que: (1) a etnometodologia é desprovida de conteúdo teórico relacionado com a Sociologia; (2) ignora fatores institucionais, uma vez que se concentra na interação social em particular, focando nas descrições das formas pelas quais os atores individuais e os estudantes explicam suas ações; (3) afirma que nenhuma abordagem objetiva generalizante é possível nas ciências sociais; (4) nunca procurou fazer-se aceitar na Sociologia e é composta por fiéis devotos unidos numa crença; (5) se interessa por problemas triviais.

Tendo em vista o alto grau de severidade empregado por Coser ao tratar da etnometodologia, esse discurso gerou uma resposta, que foi dada no ano seguinte, na forma de debate acalorado, no qual se pronunciaram não só etnometodólogos, mas também quantitativistas. Na réplica, Zimmerman (1976) menciona que Coser não quis admitir que a Sociologia americana estava em crise e, por isso, o presidente se ateve a questões cerimoniais como a alusão a trabalhos consagrados da Sociologia e a redução da ideia de medida às técnicas estatísticas. Além disso, Zimmerman (1976) comenta que Coser focou em exemplos pontuais e não explorou a essência da etnometodologia que permeia esses exemplos, o que pôde ser observado quando o presidente enfatizou as questões de trivialidade. Para Zimmerman (1976), Coser (1975) não compreendeu a etnometodologia (não soube distinguir questões como: conteúdo e forma da interação social - foco no como os indivíduos empreendem suas ações). Com relação a sugerir que a etnometodologia é uma seita, Zimmerman (1976) se defende ao elucidar que "a etnometodologia é um movimento intelectual que, como os outros, nasce na obscuridade e acaba sendo conhecido por um público mais amplo" (COULON, 1995, p. 122). Esse autor também defende que a etnometodologia se interessa pelos mesmos fenômenos que a Sociologia, mas com perspectiva diferente, uma vez que a Sociologia tradicional aborda as estruturas sociais como fatos sociais objetivos e peremptórios, enquanto a etnometodologia, ao contrário, afirma que as estruturas sociais objetivas e peremptórias são constituídas por atividades sociais estruturantes que se denominam práticas, métodos e modos de proceder - sendo exatamente as atividades estruturantes ignoradas pela Sociologia tradicional na época (COULON, 1995).

Com relação às considerações de Coser que apontam que a etnometodologia não ensina muita coisa, Mehan e Wood (1976) explicam que, se existem alguns autores que se voltaram para a etnometodologia, é exatamente porque a sociologia tradicional não esclarece suficientemente as práticas sociais que pretende compreender, ao passo que a etnometodologia pode chegar a isso pondo a nu as práticas que estruturam a vida cotidiana e saber como é que essas estruturas sociais que operam na vida de todos os dias permitem aos agentes mudá-las (COULON, 1995). E mais: esses autores salientam que a Sociologia tradicional foi construída na época do triunfo do Positivismo e, agora, deve ser reinventada, com o intuito de adaptar-se a uma nova imagem da pesquisa rigorosa. 
Garfinkel propõe um novo olhar para a Sociologia, enfatizando o foco na prática, como pode ser observado no seguinte trecho: "minha etnometodologia não é primariamente uma disciplina de leitura, escrita e fala; ela pode ser mais bem compreendida ao ser feita" (MEHAN e WOOD, 1976, p. 18, tradução nossa). Entretanto, o que torna a concepção de realidade construída da etnometodologia problemática é a sua ênfase no caráter de circunscrição estritamente situacional das ações da vida prática, o qual pode erradicar todo um substrato social, cultural e institucional fundamental para o entendimento de qualquer arranjo organizacional (SCOTT, 2008). Levada a efeito, aceitar plenamente tal circunscrição é praticamente aceitar que nada perdura além de um determinado tempo e de um determinado espaço [ou seja, a não consideração de fatores e lógicas institucionais "transtemporais" (THORNTON e OCASIO, 2008), o que mina, por sua vez, a própria natureza de tecido social que tem sua parcela de produção e reprodução na vivência cotidiana das organizações (COHEN, 1999; GIDDENS, 2003).

\section{Considerações Finais}

Diante do exposto, as descrições pormenorizadas que a etnometodologia pretende fazer para entender os métodos práticos aos quais os indivíduos recorrem para desenvolver o que realizam no seu cotidiano acaba por sugerir que essa abordagem efetua, na realidade, uma microssociologia (HERITAGE, 1999). A despeito de associações deste termo com questões de trivialidade (COSER, 1975), o que esta abordagem se propõe a fazer é desvelar, partindo do nível mais micro de análise - que é o nível interacional - os processos pelos quais as estruturas que condicionam as ações humanas são formuladas e sustentadas, sob uma lógica recursiva (GIDDENS, 2003), apoiando-se, para tal, numa revisão e apropriação de elementos e pressupostos teóricos e filosóficos contrários àqueles vigentes na Sociologia tradicional da época em que esse tipo de estudo surgiu. Não se trata, portanto, nem de uma teoria, nem de um corpo de técnicas ou métodos específicos de pesquisa - elementos que versam e se debruçam basicamente sobre a coleta de material empírico na pesquisa social -; mas sim de uma outra concepção de como fazer pesquisa social, constituindo, por isso, uma outra postura e perspectiva intelectual para com esse tipo de atividade profissional, visando à superação de dicotomias e de paradigmas epistemológicos (COULON, 1995; RAWLS, 2008; SHARROCK, 2003).

Conforme foi exposto neste ensaio, a tentativa de romper com o paradigma positivista atuante foi tão forte que - ao longo das décadas seguintes aos primeiros estudos aqui relatados - inúmeras outras possibilidades de campos de pesquisa e de fenômenos sociais foram sendo vislumbradas por sociólogos influenciados pelas ideias e concepções etnometodológicas, resultando, assim, numa gama de combinações de métodos, técnicas e objetos de estudo para a etnometodologia (MAYNARD e CLAYMAN, 1991)) - indicando, assim, tanto um desenvolvimento saudável desta perspectiva, quanto uma indicação de que se trata, efetivamente, de uma abordagem competente para empreender estudos que genuinamente expliquem e interpretem a realidade organizacional de uma maneira, se não mais robusta e convincente, ao menos diferenciada (SAMRAFREDERICKS e BARGIELA-CHIAPPINI, 2008). Contemporaneamente, discute-se não apenas a ampliação dos campos de pesquisa da etnometodologia, mas também a identificação de pontos de intersecção e de interfaces de diálogo entre a etnometodologia e correntes filosóficas e sociológicas caras àquela, como por exemplo, a filosofia pragmatista norte-americana e o socioconstrutivismo com base na fenomenologia social de Alfred Schutz (BERGER e LUCKMANN, 2003; MEYER, 2006; EMIRBAYER e MAYNARD, 2010) ainda que de maneira cautelosa (RAWLS, 2010)

Como qualquer perspectiva teórica que se proponha a questionar uma conduta intelectual dominante, a etnometodologia não pôde passar sem críticas às suas concepções metodológicas (HAK, 1995; COHEN, 1999), apropriações e amarras filosóficas (BAUMAN, 1973), e intenções de superação de dicotomias (HOLSTEIN e GUBRIUM, 1994; RAWLS, 2008). Contudo, em termos de circunscrição epistemológica das críticas - ou seja, sua natureza de crítica interna ou externa à perspectiva indagada -, acredita-se que esse exercício de questionamento seja saudável e profícuo, por possibilitar um desenvolvimento teórico e 
melhorias no cerne da própria perspectiva em si, sempre respeitando que toda abordagem é, inevitavelmente, uma escolha epistemológica, teórica e metodológica (CILLERS, 2002) para como abordar e explicar o complexo fenômeno da realidade da vida social cotidiana.

Além disso, cabe ainda discutir, em termos de considerações finais, a importância dessa abordagem para os estudos organizacionais. Tem-se discutido a natureza das organizações como produtos de uma realidade socialmente construída, constituídas nas interações dos sujeitos e pautadas em um contexto intersubjetivo de compartilhamento de significados, a partir dos quais as ações organizacionais e individuais adquirem relevância e significado. Ao mesmo tempo, tem-se retomado a ideia de que as organizações são constituídas por pessoas em suas práticas cotidianas e só existem a partir delas em um processo de construção e reconstrução constantes. Logo, as organizações, enquanto fenômeno, estão relacionadas ao seu lugar na existência nesse mundo cotidiano, e a compreensão do fenômeno organizacional exige que se olhe para ele de forma teórica e metodológica adequada. Diante disso, a etnometodologia parece ser uma possibilidade de aproximação do fenômeno organizacional que permite compreendê-lo de forma adequada, quando as organizações são entendidas conforme se descreveu acima - como sendo realizações de agentes em suas práticas cotidianas, existentes a partir de um processo de (re)construção ativa constante, intercalando dialeticamente seus elementos estruturantes (num entendimento das organizações como verbo) e estruturados (num entendimento das organizações como substantivo) (TSOUKAS e CHIA, 2002). Ao mesmo tempo, é uma abordagem teórico-metodológica, que, conforme se expôs aqui, ainda precisa de discussões que possam esclarecer seus delineamentos, os métodos adequados aos seus pressupostos e, fundamentalmente, estudos organizacionais de base etnometodológica sérios e rigorosos capazes de trazer desenvolvimentos tanto em termos de resultados para a compreensão do fenômeno organizacional, quanto com relação aos desenvolvimentos da etnometodologia como abordagem teórico-metodológica. Um exemplo dessa problemática de pesquisa são os desafios (seguindo uma postura etnometodológica) em se realizar conversações entre níveis de análise da realidade das organizações, evitando-se apenas o nível micro, contemplando as relações com o nível macro no qual as organizações estão situadas, e ainda relacionando-os com o nível meso, no qual se situam as práticas cotidianas (COULTER, 2001).

Em publicações reconhecidas no campo dos estudos organizacionais, é perceptível uma recente retomada de pesquisas etnográficas cuja inclinação etnometodológica se faz explícita (LANZARA, 2009; LLEWELLYN e SPENCE, 2009; MIETTINEN, SAMRA-FREDERICKS e YANOW, 2009). Sendo assim, acredita-se que este ensaio deixa como contribuição um convite para estudos futuros que consigam delinear desenvolvimentos nessas frentes, ao mesmo tempo em que apresenta essa abordagem teórico-metodológica como possibilidade para os estudos organizacionais que buscam a compreensão das mesmas a partir da noção de práticas sociais.

\section{Referências}

BAUMAN, Z. On the philosophical status of ethnomethodology. The Sociological Review, v. 21, n. 1, p. 5- 23, 1973.

BERGER, P. L.; LUCKMANN, T. A construção social da realidade. 26. ed. Petrópolis: Vozes, 2003.

CILLERS, P. Why we cannot know complex things completely. Emergence, v. 4, n. 1/2, p. 77-84, 2002.

COHEN, I. J. Teoria da estruturação e práxis social. In: GIDDENS, A.; TURNER, J. (Org.). Teoria social hoje. São Paulo: Editora UNESP, 1999. p. 393-446.

COSER, L. A. Presidential address: two methods in search of a substance. American Sociological Review, v. 40, n. 6, p. 691-700, 1975 .

COULON, A. Etnometodologia. Petrópolis: Vozes, 1995. 
COULTER, J. Human practices and the observability of the 'macro-social'. In: SCHATZKI, T. R.; KNORR CETINA, K.; SAVIGNY, E. von. (Ed.). The practice turn in contemporary theory. London: Routledge, 2001. p. 29-41.

EMIRBAYER, M.; MAYNARD, D. W. Pragmatism and ethnomethodology. Qualitative Sociology Online First Symposium on Emirbayer and Maynard's "Pragmatism and Ethnomethodology", 22. Nov. 2010.

GARFINKEL, H. Studies in ethnomethodology. New Jersey: Prentice Hall, 1967.

GIDDENS, A. A constituição da sociedade. São Paulo: Martins Fontes, 2003.

HAK, T. Ethnomethodology and the institutional context. Human Studies, v. 18, n. 2/3, p. 109-137, 1995.

HERITAGE, J. Etnometodologia. In: GIDDENS, A.; TURNER, J. (Org.). Teoria social hoje. São Paulo: Editora UNESP, p. 321-392, 1999.

HOLSTEIN, J. A.; GUBRIUM, J. F. Phenomenology, Ethnomethodology, and Interpretive Practice. In: DENZIN, N. K.; LINCON, Y. S. (Ed.). Handbook of qualitative research. 2 ed. Bevery Hills, CA: Sage Publications Inc., 1994. p. $262-272$

JOAS, H. Interacionismo simbólico. In: GIDDENS, A.; TURNER, J. (Org.). Teoria social hoje. São Paulo: Editora UNESP, p. 127-174, 1999.

LANZARA, G. F. Reshaping practice across media: material mediation, medium specificity and practical knowledge in judicial work. Organization Studies, v. 30, n. 12, p. 1369-1390, 2009.

LLEWELlYN, N.; SPENCE, L. Practice as a members' phenomenon. Organization Studies, v. 30, n. 12, p. 14191439, 2009.

LYNCH, M.; PEYROT, M. Introduction: a reader's guide to ethnomethodology. Qualitative Sociology, v. 15, n. 2, p. 113-122, 1992.

. Ethnomethodology and the logic of practice. In: SCHATZKI, T. R.; KNORR CETINA, K.; SAVIGNY, E. von. (Ed.). The practice turn in contemporary theory. London: Routledge, 2001. p. 131-148.

MAYNARD, D. W.; CLAYMAN, S. E. The diversity of ethnomethodology. Annual Review of Sociology, v. 17, p. 385-418, 1991.

MEHAN, H.; WOOD, H. De-secting ethnomethodology. The American Sociologist, v. 11, n. 1, p. 13- 21, 1976.

MENNELL, S. Ethnomethodology and the new Methodenstreit. Acta Sociologica, v. 18, n. 4, p. 287-302, 1975.

MERLEAU-PONTY, M. Fenomenologia da percepção. São Paulo: Martins Fontes, 1999.

MEYER, R. E. Visiting relatives: current developments in the new sociology of knowledge. Organization, v. 13, n. 5, p. 725-738, 2006.

MIETTINEN, R.; SAMRA-FREDERICKS, D.; YANOW, D. Re-turn to practice: an introductory essay. Organization Studies, v. 30, n. 12, p. 1309-1327, 2009.

MONTENEGRO, L. M. Construção de sentidos (sensemaking) em práticas de um processo estratégico: um estudo comparativo em duas instituições de ensino superior do estado do Paraná. 2009. 205p. Dissertação (Mestrado em Administração) - Universidade Federal do Paraná, Curitiba, PR, 2009.

PSATHAS, G. Alfred Schutz's influence on American sociologists and sociology. Human Studies, v. 27, n. 1, p. 1-35, 2004. 
RAWLS, A. W. Harold Garfinkel, ethnometodology and workplace studies. Organization Studies, v. 29, n. 5, p. 701732, 2008.

. Garfinkel, ethnomethodology and the defining questions of pragmatism. Qualitative Sociology Online First Symposium on Emirbayer and Maynard's "Pragmatism and Ethnomethodology", 22. Nov. 2010.

ROBICHAUD, D.; GIROUX, H.; TAYLOR, J. R. The metaconversation: the recursive property of language as a key to organizing. Academy of Management Review, v. 29, n. 4, p. 617-634, 2004.

SAMRA-FREDERICKS, D.; BARGIELA-CHIAPPINI, F. Introduction to the symposium on the foundations of organizing: the contribution from Garfinkel, Goffman and Sacks. Organization Studies, v. 29, n. 5, p. 653-675, 2008.

SCOTT, W. R. Institutions and organizations: ideas and interests. 3. ed. Thousand Oaks: Sage, 2008.

SHARROCK, W. Fundamentals of ethnomethodology. In: RITZER, G.; SMART, B. (Ed.). Handbook of social theory Thousand Oaks: Sage Publications, 2003. p. 249-259.

THORNTON, P. H.; OCASIO, W. Institutional logics. In: GREENWOOD, R.; OLIVER, C.; SAHLIN, K.; SUDDABY, R. (Ed.). The SAGE Handbook of organizational institutionalism. Thousand Oaks: Sage Publications, 2008. p. 99-129.

TSOUKAS, H.; CHIA, R. On organizational becoming: rethinking organizational change. Organization Science, v. 13, n. 5 , p. 567-582, 2002.

WEICK, K. Sensemaking in organizations. Thousand Oaks: Sage Publications, 1995.

WITTGENSTEIN, L. Investigações Filosóficas. 6. ed. Petrópolis: Vozes, 2009.

ZIMMERMAN, D. H. A reply to professor Coser. The American Sociologist, v. 11, n. 1, p. 4-13, 1976.

. Ethnomethodology. The American Sociologist, v. 13, Feb. p.6-15, 1978. 